\title{
,neu \\ Design and Evaluation of Vacuum Central Drum Seed Metering Device
}

\author{
Baolong Wang ${ }^{1}$, Yi Na ${ }^{1}$, Jian Liu ${ }^{1}$ and Zaiman Wang ${ }^{2, *}$
}

Citation: Wang, B.; Na, Y.; Liu, J.; Wang, Z. Design and Evaluation of Vacuum Central Drum Seed Metering Device. Appl. Sci. 2022, 12, 2159. https://doi.org/10.3390/ app12042159

Academic Editor: Luigi Fortuna

Received: 15 January 2022

Accepted: 16 February 2022

Published: 18 February 2022

Publisher's Note: MDPI stays neutral with regard to jurisdictional claims in published maps and institutional affiliations.

Copyright: (C) 2022 by the authors. Licensee MDPI, Basel, Switzerland. This article is an open access article distributed under the terms and conditions of the Creative Commons Attribution (CC BY) license (https:// creativecommons.org/licenses/by/ $4.0 /)$.
1 School of Horticulture, Hainan University, Haikou 570228, China; wangbaolong@hainanu.edu.cn (B.W.); nygreeny@163.com (Y.N.); liujian99@hainanu.edu.cn (J.L.)

2 Key Laboratory of Key Technology on Agricultural Machine and Equipment, Ministry of Education, South China Agricultural University, Guangzhou 510642, China

* Correspondence: wangzaiman@scau.edu.cn

\begin{abstract}
For the purpose of reducing the number of conventional seed-metering devices and high demand for vacuums, this study designed a vacuum central drum seed-metering device, that is intended to replace multiple seed-metering devices with one, which is comprised of the inner and outer drum. This can be replaced with different diameters of suction holes, ventilation housing, seeding tube, agitating devices, seed box, and seed-cleaning devices, etc. A hybrid rice seed Jingliangyou 1212 was applied as an experimental material, and a JPS-12 computer vision metering device test bench was used to test singular-factor and multi-factor seeding performance of the seedmetering device. The singular-factor performance test of the metering device was conducted under negative pressure of seed suction in the range of $1 \sim 1.5 \mathrm{kPa}$, at the metering device rotation speed of $10 \sim 60 \mathrm{rpm}$, with diameters of inlet holes being $2 \mathrm{~mm}$ (chamfer: $45^{\circ}$ ), 2, and $1.5 \mathrm{~mm}$, respectively. The number of seeds was counted by a sucking hole under different factor combinations. The multifactor test was carried out by rotation rate, negative pressure, and types of sucking holes. A rate of $2 \pm 1$ rice seed per sucking hole is regarded as the qualified standard. It shows that the qualification rate ( $2 \pm 1$ rice seed per sucking hole) of seed suction can reach $97.4 \%$ under a combination of metering device rotation speed of $30 \mathrm{r} / \mathrm{min}$, negative pressure of $1.0 \mathrm{kPa}$, and suction hole diameters of $1.5 \mathrm{~mm}$. High-speed photography was used to study the trajectory of seed-metering at different rotation rates, a locomotive axis was applied to fit the motion curve, and 3D-printing was used to make the seed-metering tube so that the seed collisions could be reduced. This study provides evidence for further optimizing the performance of the vacuum central drum direct-seeding machine for hybrid rice.
\end{abstract}

Keywords: hybrid rice; vacuum; central drum; metering device

\section{Introduction}

Rice-planting mechanization is an important part for realizing the complete mechanization of rice production. Rice-planting mechanization mainly includes three patterns: mechanized transplanting, throwing, and direct seeding. Chinese mechanized direct sowing technology of rice has achieved significant development in recent years, of which the precision rice hill-drop drilling technology has been promoted over a wide area due to its advantages of saving time and work, well ventilated fields, fewer pests, low tillering node in rice, and even uniform growth [1-4].

Hybrid rice, owing to its features of strong tillering ability and high production, has obtained a wide popularization in China. In 2013, the planting area of hybrid rice reached 16.1787 million hectares, accounting for $53.37 \%$ of the total planting area of rice in China $[5,6]$. Current mechanical seed-metering devices are mainly designed for medium or large seeding amount requirements, which makes it hard to meet the technical requirements of precise seeding of hybrid rice. Vacuum seed-metering devices are suitable for 
precise seeding due to its characteristics of less bud damage and strong adaptability to the dimensions of rice seeds.

To improve the performance of the seed-metering devices, a vertical disc seed-metering device with the linear-type and guide-type seed-agitating mechanism was tested [7-10]. A vacuum centralized seed-agitating device for rapeseed and wheat was developed and the major factors of the seed-agitating device affecting the seed filling performance were analyzed, the main structural parameters of the agitating device and agitating axle were determined, and the impact of the structure and configuration of the agitating device on the filling performance were investigated by means of DEM-simulated analysis and bench test [11]. The discrete element method was applied to perform simulated analysis on the seed dispersion in the seed-metering device, acting force between the seeds, and the moving speed of the seeds [12]. To address the problems of high damage rate, low seeding accuracy, and poor seeding generally in the seeding process, a general-purpose seeding device was designed in this study that was based on the principle of mechanical vacuum combined seeding. The air-blowing-type cleaning and seed unloading of the device laid the conditions for precise seeding and flexible seeding [13]. According to the agronomic requirements of garlic sowing, the garlic morphology was studied and a garlic seed-metering mechanism with excellent seeding performance was designed where a new garlic seeding machine with an adjustable-size seeding device was developed to realize an efficient single-seed-metering and seeding of different varieties of garlic [14].

Extensive studies have been made on the working parameters of seed-metering devices during the seed-suction process, but the studies on vacuum drum seed-metering devices did not involve hybrid rice, and the traditional seed-metering system requires a plurality of seed-metering devices; it has a complex structure and high requirements for vacuums [15-25].

According to the technical route of vacuums, one can replace multiple seed-metering devices. This study takes structure design, theoretical analysis, experimental design, and high-speed photography as technical means to investigate the mechanism of a drummetering device from the perspective of suction, transportation, and seed-metering. The singular-factor experiment was conducted to test seed-metering performance of different types of inlet hole, drum rotation rate, and negative pressure of suction chamber. The trajectory of seed-metering was also studied by adopting technical means such as highspeed photography, $5 \times 5 \mathrm{~mm}$ reference grid to record the motion track of seed-metering at different moments, and Excel to draw the track of seed-throwing so that equation models can be deduced. Then, the equation model of seed-dropping can optimize the seed-metering tube.

\section{Structure and Working Principle}

\subsection{Structure}

According to the technical requirements of the vacuum central drum seed-metering device (take $2 \pm 1$ rice seeds per suck hole as the qualified standard), a vacuum central drum seed-metering device, which can be applied to the direct-seeding of hybrid rice with high quality and small quantity and has the central drum character (singular device sowing multiple rows), was designed.

Comparatively few studies have been conducted domestically and overseas about vacuum central drum hybrid rice precise-seeding, and the existing hybrid rice metering devices are dominated by round disc devices. Therefore, this study designed a vacuum central drum seed-metering device, As shown in the Figure 1, in which the central drum seed-metering device is mainly composed of 1 . a seed box, 2 . an outer drum, 3 . ventilation housing (connect the positive and negative pressure pipes, respectively), 4 . seeding tubes (a seed discharge channel), and 5. an air delivery port (for blowing seeds to different rows). 


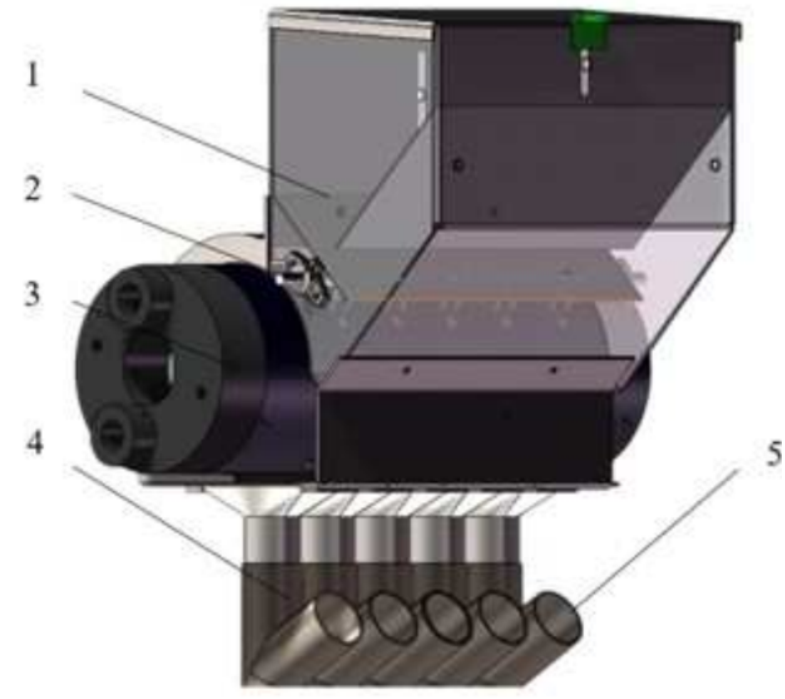

Figure 1. The main structure of the rice-metering device. 1. seed box, 2. outer drum, 3. ventilation housing, 4. seeding tubes, and 5. air delivery ports.

\subsection{Working Principle}

Figure 2 shows the working principle of the vacuum central drum seed-metering device. The tractor's power output drives the inner (bigger vacuum hole) and outer drum (replaceable outer drum for different diameters of suction hole) to rotate, and the fixed ventilation housing (connecting the positive and negative pressure pipes, respectively) has positive and negative pressure cavities with which the inlet and outlet of the port are connected, respectively. The suction hole of the drum in the negative pressure zone sucks the rice seeds in the seed box, and the surplus rice seeds fall into the seed box under the action of the seed cleaning device. The sucked rice seeds enter the positive pressure zone with the rotation of the drum, falling into the seeding tubes under the action of self-weight and positive pressure, and then fall into the sowing groove under the effects of self-weight and positive pressure.

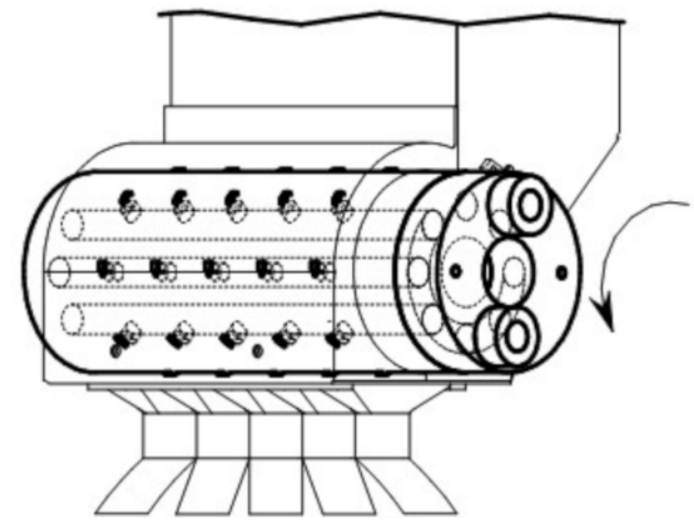

Figure 2. Schematic diagram of the seeding process by the vacuum central drum seed-metering device.

\section{Key Component Parameter Design and Analysis}

\subsection{Determination of Seed Sucking Hole Size}

Analysis of papers that are related to vacuum seed-metering devices shows that the diameter of the seed-suction hole has a direct impact on the performance of seed suction; the diameter of seed suction hole presents a negative cubic relationship with the inlet hole, and the diameter of the inlet hole plays a pivotal role on the performance of the 
vacuum-metering device. The diameter of the established suction hole that was measured by experimental methods is:

$$
d=(0.6-0.7) b
$$

Rice seeds are slim, long, and pointed with arris, awn, and tomentum, presenting a spindle shape. A suction hole that is too small may easily lead to blockage, while being too big easily leads to resown and stuck seeds. According to the size of the hybrid rice cultivar, Ruanhuayou1179, Shunliangyou1179, Jingliangyou 1212, Teyou338, and Wuyou1179 (Table 1) and Equation (1), the diameter of suction hole can be determined as $1.4 \sim 1.8 \mathrm{~mm}$.

Table 1. The average triaxial size of six varieties hybrid rice seeds.

\begin{tabular}{cccc}
\hline Cultivar & Average Length/mm & Average Width/mm & Average Thickness/mm \\
\hline Ruanhuayou1179 & 9.82 & 2.28 & 1.82 \\
Shunliangyou1179 & 9.72 & 2.64 & 2.04 \\
Jingliangyou 1212 & 8.48 & 2.42 & 1.85 \\
Teyou338 & 8.22 & 2.87 & 2.14 \\
Wuyou1179 & 8.62 & 2.56 & 1.99 \\
\hline
\end{tabular}

\subsection{Determination of Seeding Drum Parameters}

The inner and outer drum and the ventilation housing are installed coaxially. As indicated in Figure 3, the fixed ventilation housing (7) is attached to the inner drum (4) and the outer drum (1), and the inner cavity of the ventilation housing (7) is divided into a negative pressure zone (5) and a positive pressure zone (6). The suction hole of the seeding drum rotates to the negative pressure zone (5) sucks the rice seeds that are in the seed box, while the surplus rice seeds fall into the seed box under the action of the seed cleaning box. The sucked rice seeds enter the positive pressure zone (6) with the rotation of the drum, falling into the seeding tube due to self-weight and positive pressure, and then by self-wight and positive pressure circulation, the rice seeds fall into the sowing groove that is dug by the ditch-digging and ridge-forming base slab.
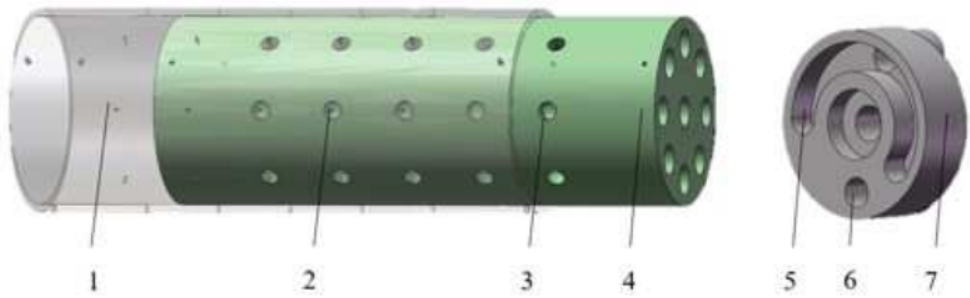

Figure 3. The main structure of the seeding drum. 1. the outer drum, 2. the outer suction holes, 3 . The inner suction holes, 4 . the inner drum, 5 . the negative pressure zone, 6 . the positive pressure zone, and 7. the ventilation housing.

The circular velocity of the drum is the basis for determining the drum diameter, and the rotation speed of the seeding drum has certain numerical relationships with the forward velocity of the metering device [26].

The seeding quantity of the metering device per second is:

$$
Q_{m}=\frac{V_{g}}{D+\Delta L}
$$

The seeding quantity of the metering device per second can be represented by the forward velocity $V_{m}$ and the hole distance $T$ :

$$
Q_{m}=\frac{V_{m}}{T}
$$


Eliminate $Q_{m}$ in Equations (2) and (3):

$$
V_{g}=\frac{V_{m}(D+\Delta L)}{T}
$$

Therefore, the diameters of the drum can be obtained as:

$$
D_{g}=\frac{ \pm 60 V_{m}(D+L)}{\pi N T}
$$

The number of suction holes is:

$$
Z=\frac{\pi D_{g} K}{D+\Delta L}
$$

The circumferential distance between two adjacent holes is represented by $D+\Delta L$, which should be longer than the maximum size of two rice seeds, namely:

$$
D+\Delta L \geq 2 \operatorname{lmax}
$$

It can be seen from Equations (3) and (4) that when the forward velocity of the seeder $V_{m}$ and the hole distance is constant, the diameter of the drum is inversely proportional to the rotation rate. The decrease of the rotation rate can prolong the seed-filling time, but as the diameter increases, the required air flow must be increased, and then air leakage loss also rises. Reducing the diameter can decrease the height of the seed layer in the seed box and influence the seed-filling performance, and the material of the drum should be taken into consideration as well. The forward velocity of the direct-seeding seeder in the paddy field is generally $0.5 \sim 1.5 \mathrm{~m} / \mathrm{s}$, therefore, the curve length between two holes $D+\Delta L \geq 0.02 \mathrm{~m}$. According to the ratio of output speed of the riding type rice tractor head and the rotation rate of the gear box, the rotation rate being $0 \sim 60 \mathrm{rpm}$ corresponds to a forward velocity of the direct-seeding seeder being $0 \sim 1.0 \mathrm{~m} / \mathrm{s}$, and the sowing hole distance of hybrid rice is generally between 0.14 and $0.18 \mathrm{~m}$. The diameter of the drum can be estimated from Equation (5), and by taking factors such as the transmission system of existing hybrid rice direct-seeding seeders into overall consideration, it is appropriate to choose an external diameter as $135 \mathrm{~mm}$. On the basis of a double-layer drum structure of the metering device, the outer layer is easy to replace, and the size and shape of the suction hole of the drum can be changed to meet the requirements of different hybrid rice types and different sowing quantities.

\subsection{Ventilation Housing}

The vacuum central drum-metering device adopts the negative pressure for sucking the seeds, positive pressure for seed cleaning and seed delivery method. The ventilation housing and the drum coaxial installation also rely on the combination of mutual pressure and the dynamic friction; the ventilation housing as shown in Figure 4.

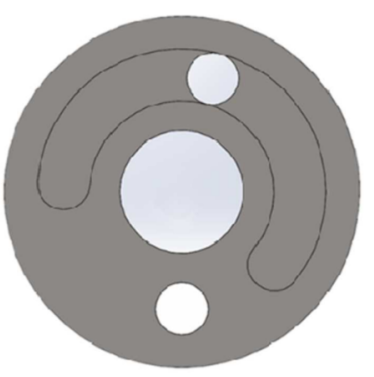

(a)

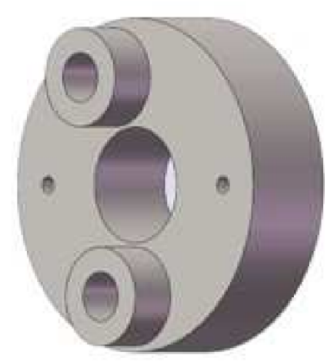

(b)

Figure 4. The main structure diagram of the ventilation housing. (a) Front view and (b) side view. 
The seeding drum rotates clockwise and the corresponding air chamber channel and suction hole on the seeding drum rotate to $33^{\circ}$ below the centre line of the air exchange shell, where the suction hole enters the vacuum suction seed area. The corresponding suction hole on the seeding drum completes the suction of the rice seed in this arc section where the sucked rice seed turns over the seed carrying area under the protective effect of negative pressure and continues to rotate to the seed dropped zone. The seed then enters the seed-carrying arc section where the negative pressure disappears and the rice seed, under the action of gravity and positive pressure, enters the seed discharge tube and is blown to the sowing furrow. After the seed is dropped, the suction hole enters the emptying zone ready for the next cycle; the functional division is shown in Figure 5.

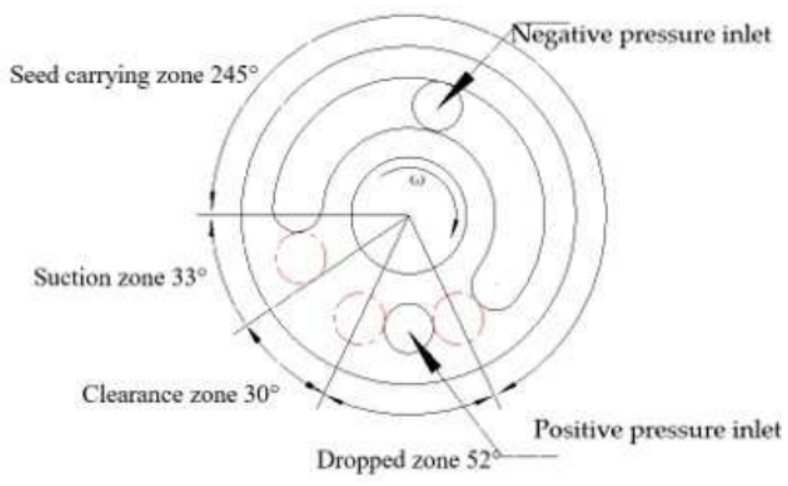

Figure 5. The zone map of the ventilation housing.

\subsection{Seed-Agitating Mechanism}

Rice seeds are thin, long, pointed, angular, awned, and downy, and have poor mobility. The drum-type metering device has problems, such as short seed suction time and the tendency to form cavity areas in the seed box, which is not conducive to the adsorption of rice seed. An electromagnetic excitation device was installed in the bottom of the seed box in a preliminary laboratory experiment to facilitate seed suction by the drum-metering device, which is not suitable for application in the field as this device requires electricity. A guided seed-agitating device and a linear seed-agitating device on a vertical disc rice vacuummetering device have been applied $[7,8]$. The experimental results showed that the guided seed-agitating device had the effect of separating, guiding, rubbing, and supporting indica rice seeds, which could improve the seed rowing accuracy of the seed-metering device.

The previous experimental study found that if the thickness of the seed-agitating device is too large [25], the rice seed is easily carried by the seed-agitating device, but the seed-agitating effect becomes worse if the thickness of the seed-agitating device is too thin. For this reason, this paper designed a seed-agitating device with a curved slope for rice vacuum drum seed dispersers, as shown in Figure 6. On the basis of the vertical disc-guided and linear seed-agitating devices, three kinds of agitating devices were designed with an arc-shaped inner and outer radian adhering to the outer surface of the drum, a suction hole on the side of the device that was made by a 3D-printing machine using ABS material, of which the thinnest part of the c-type seed-agitating device with a slope that is $1 \mathrm{~mm}$ thick, and the maximum thickness that is $2 \mathrm{~mm}$; the structure is shown in Figure 6c. The uniform thickness of $2 \mathrm{~mm}$ and $1 \mathrm{~mm}$ agitating mechanism are shown in Figure 6a,b, respectively, and the structure of Figure $6 \mathrm{c}$ was chosen as the basis for testing according to the authors' previous experiments and parameter optimization of the agitating mechanism. 


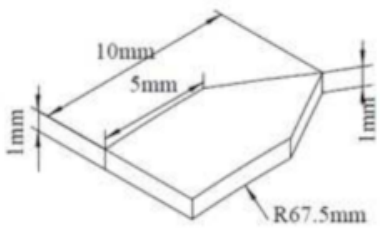

(a)

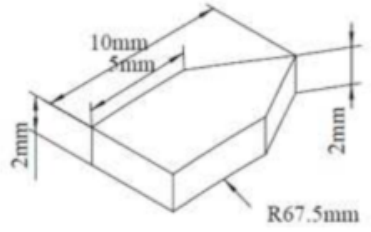

(b)

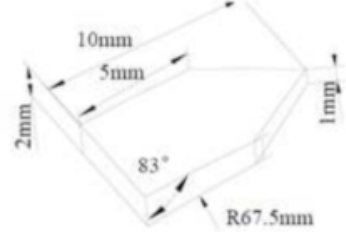

(c)

Figure 6. The wedge-type agitating device. (a) $1 \mathrm{~mm}$ agitating device, (c) $2 \mathrm{~mm}$ agitating device, and (b) $1 \sim 2 \mathrm{~mm}$ arc-shaped agitating device.

\subsection{Seed Cleaning Mechanism}

A vacuum-metering device is the same as a mechanical-metering device and requires the use of a seed cleaner to remove any excess seeds and achieve quantitative sowing. In this paper, a double-sided curved seed scraping mechanism was used to remove the excess rice seeds from both sides of the suction holes in the axial direction of the drum. The seed that is attached to the suction holes rotates with the drum and the excess seed slips back into the seed box under the mechanical force of the curved seed scraper. According to the amount of seed that is used per hole and the friction angle between the rice seed and the drum material, etc., a double sided seed cleaning mechanism is set up, with the horizontal angle of $40^{\circ}$ and $35^{\circ}$, respectively, and the two seed cleaning members are spaced $2.50 \mathrm{~mm}$ apart from the suction holes, as shown in Figure 7.

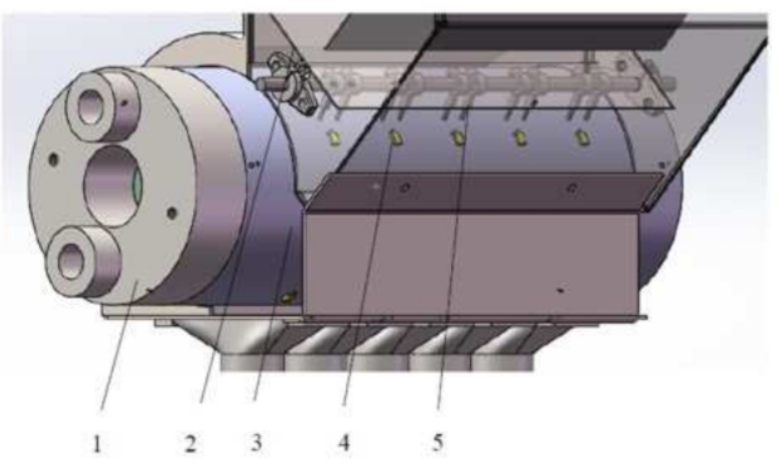

Figure 7. Sketch map of the agitating device arrangement. 1. the ventilation housing, 2. the seed box, 3. the outer drum, 4 . the agitating devices, and 5. the cleaning devices.

\section{Seed Performance Test}

\subsection{Test Materials and Equipment}

The physical characteristics of agricultural materials are the premise and basis for the design, manufacture, and production tests of agricultural machinery, and the research on the subject has important theoretical and practical significance. The vacuum central drum seed-metering device is mainly suitable for sowing a small amount of hybrid rice varieties, and this paper selects the hybrid rice seed Jingliangyou 1212 that is planted in the rice area of South China as the test material. The seeds were soaked in water for $48 \mathrm{~h}$ and then drained in a cool place until the breasts were broken and white. A total of 1000 seeds were selected and measured three times, and the average values of the length (L), width (W), thickness (T), and thousand seed weight of Jingliangyou 1212 seeds are shown in Tables 2 and 3. When testing the seed-metering device performance in the field, the metering device was suspended and towed behind the tractor. In contrast to the metering device test platform, which has a seed bed belt as the seed bed, the metering device was stationary during the test and the seed bed moved relative to the metering device. The JPS-12 computer vision metering device performance test rig was mainly composed of the seed bed belt, stand, drive motor, oil injection pump, fan, and the metering device performance test part, as shown in Figure 8. 
Table 2. The basic physical properties of Jingliangyou 1212 rice.

\begin{tabular}{lcccccc}
\hline Varieties & $\begin{array}{c}\text { Average } \\
\text { Length/mm }\end{array}$ & $\begin{array}{c}\text { Average } \\
\text { Width/mm }\end{array}$ & $\begin{array}{c}\text { Average } \\
\text { Thickness/mm }\end{array}$ & $\begin{array}{c}\text { Moisture } \\
\text { Content/\% }\end{array}$ & $\begin{array}{c}\text { Average } \\
\text { Thousand } \\
\text { Seed Weight/g }\end{array}$ & $\begin{array}{c}\text { Standard } \\
\text { Deviation }\end{array}$ \\
\hline Jingliangyou 1212 & 8.48 & 2.42 & 1.85 & 19.13 & 21.83 & 0.21 \\
\hline
\end{tabular}

Table 3. The factor and level in experiment.

\begin{tabular}{ccccccc}
\hline & \multicolumn{5}{c}{ Levels } \\
\cline { 2 - 6 } Factor & $\mathbf{1}$ & $\mathbf{2}$ & $\mathbf{3}$ & $\mathbf{4}$ & $\mathbf{5}$ \\
\hline A Rotational speed $(\mathrm{r} / \mathrm{min})$ & 10 & 20 & 30 & 40 & 50 & 60 \\
B Negative pressure $(\mathrm{kPa})$ & 1.0 & 1.5 & 2.0 & & \\
C Holes diameter $(\mathrm{mm})$ & 1.5 & 2 & 2 (Chamfering $\left.45^{\circ}\right)$ & & \\
\hline
\end{tabular}

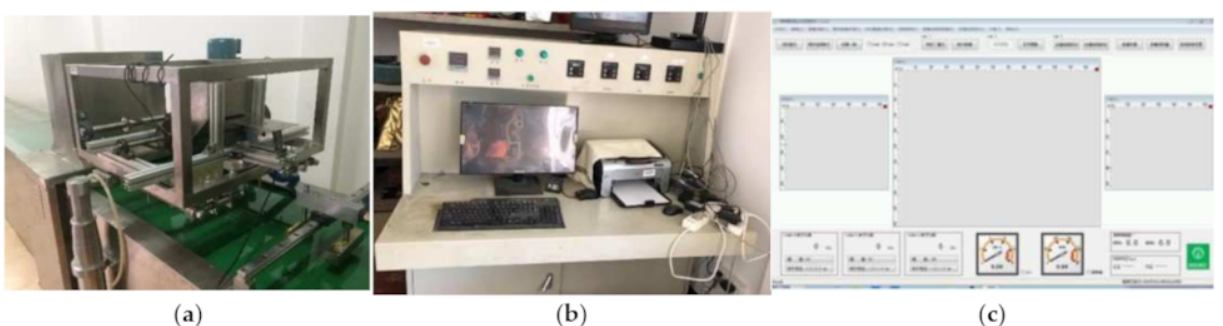

(a)

(b)

(c)

Figure 8. The main structure of JPS-12 Force analysis of seeds. (a) The test-bed, (b) operating platform, and (c) the software main interface.

\subsection{Evaluation Index}

(1) Evaluation index

According to the agronomic requirements of hybrid rice sowing, this paper takes 0 seeds/hole rate defined as missing, $2 \pm 1$ seeds/hole rate as qualified, and $\geq 4$ seeds/hole rate defined as re-seeding.

(2) Calculation method

Referring to the national standard GB/T 6973-2005, the number of seeds that were adsorbed in each hole was continuously recorded as $\mathrm{Xi}$, with 250 holes as one group and a total of three groups, the average number of seeds adsorbed in each group was calculated, and the number of times that $0,1,2,3,4,5$, and above seeds that were adsorbed in each group was recorded [27].

\subsection{Single-Factor Test}

Experiments on the Effect of Different Diameter Suction Holes on the Seed Suction Pattern

To study the influence of different suction parameters on the seed suction performance of the drum-metering device, three different suction hole parameters of the drum were machined, namely $2 \mathrm{~mm}$ suction holes with $45^{\circ}$ chamfer, $2 \mathrm{~mm}$ straight holes, and $1.5 \mathrm{~mm}$ straight holes, and the positive pressure of seed rowing was $1.5 \mathrm{kPa}$. Under different conditions of rotational speed (10-60 rpm) and suction vacuum (1.0-2.0 kPa) with a single variable tested separately. The probability of different numbers of rice seeds being sucked by each group of suction holes was counted. The data were processed using EXCEL software and plotted on a line graph as shown in Figure 9, where the horizontal coordinates are the number of different seeds that were sucked and the vertical coordinates are the probabilities of different seeds that were sucked.

The pattern of seed (rice seeds) uptake at the different speeds and different negative pressures of seed uptake is shown in Figure 9. At low speeds, the cavitation rate was low 
and increased as the negative pressure increased; as the speed increased, the probability of cavitation increased, but at this time, as the negative pressure increased, the onset of seed uptake became slightly later than that which occurs at low speeds.

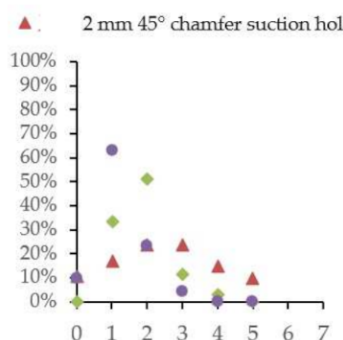

(a)

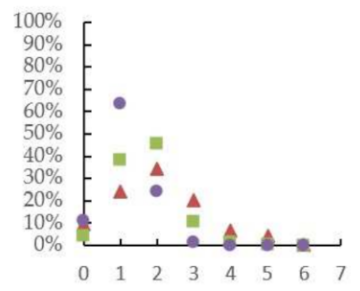

(d)

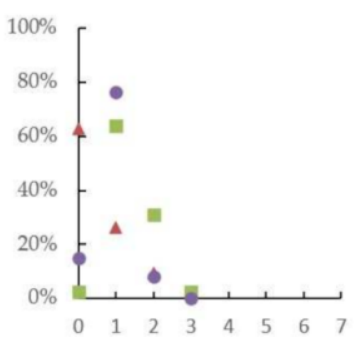

(g)

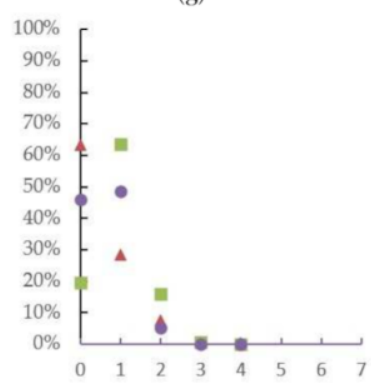

(j)

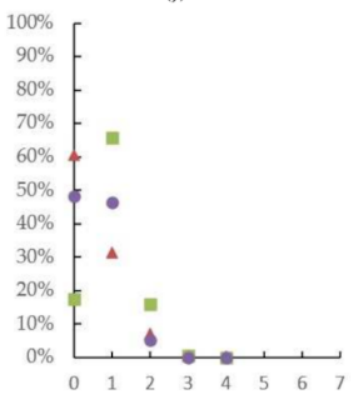

(m)

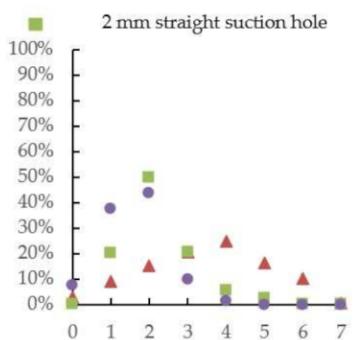

(b)

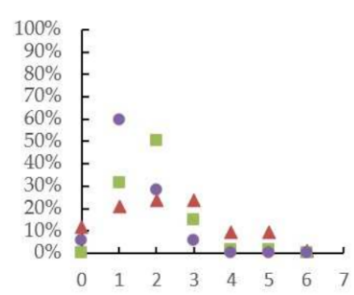

(e)

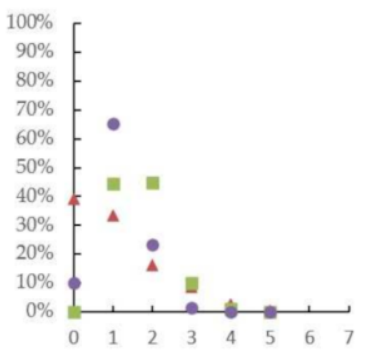

(h)

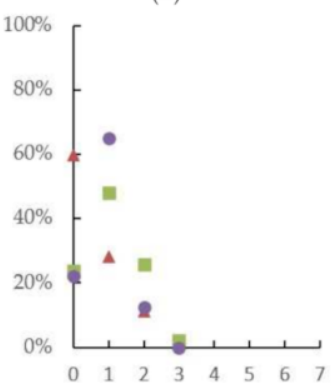

(k)

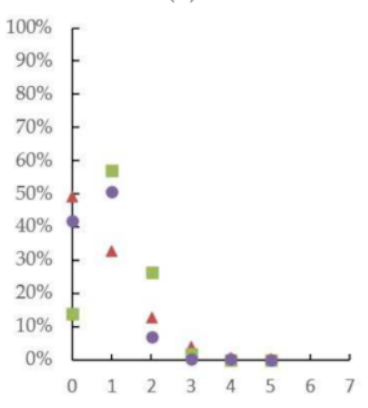

(n)

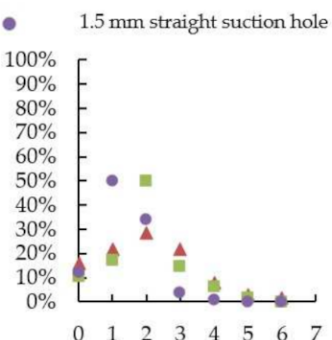

(c)

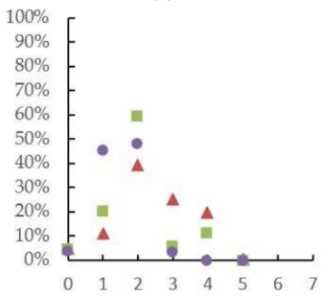

(f)

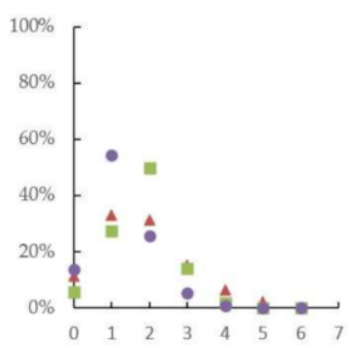

(i)

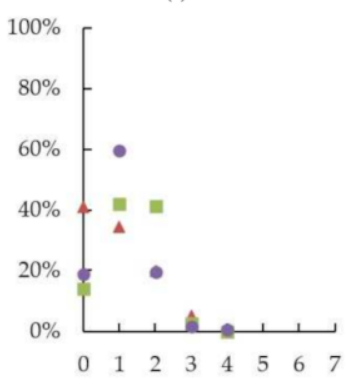

(l)

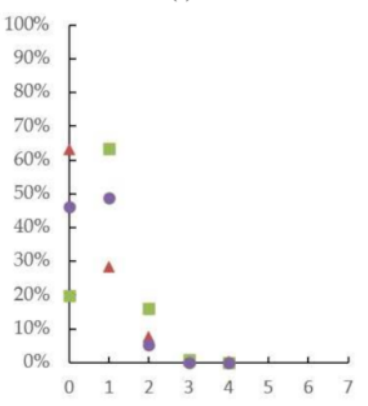

(o)

Figure 9. Cont. 


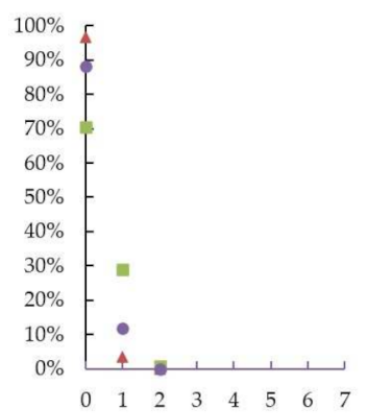

(p)

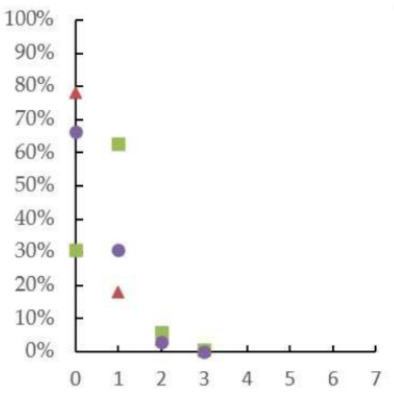

$(\mathbf{q})$

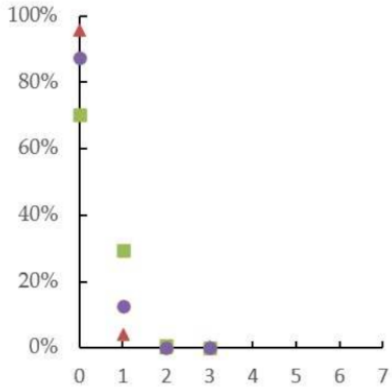

(r)

Figure 9. The sucking probability of different holes under different diameters. (a) $10 \mathrm{rpm} 1.0 \mathrm{kPa}$, (b) $10 \mathrm{rpm} 1.5 \mathrm{kPa}$, (c) $10 \mathrm{rpm} 2.0 \mathrm{kPa}$, (d) $20 \mathrm{rpm} 1 . I \mathrm{~Pa}$, (e) $20 \mathrm{rpm} 1.5 \mathrm{kPa}$, (f) $20 \mathrm{rpm} 2.0 \mathrm{kPa}$, (g) $30 \mathrm{rpm} 1.0 \mathrm{kPa}$, (h) $30 \mathrm{rpm} 1.5 \mathrm{kPa}$, (i) $30 \mathrm{rpm} 2.0 \mathrm{kPa}$, (j) $40 \mathrm{rpm} 1.0 \mathrm{kPa}$, (k) $40 \mathrm{rpm} 1.5 \mathrm{kPa}$, (l) $40 \mathrm{rpm} 2.0 \mathrm{kPa}$, (m) $50 \mathrm{rpm} 1.0 \mathrm{kPa}$, (n) $50 \mathrm{rpm} 1.5 \mathrm{kPa}$, (o) $50 \mathrm{rpm} 2.0 \mathrm{kPa}$, (p) $60 \mathrm{rpm} 1.0 \mathrm{kPa}$, (q) $60 \mathrm{rpm} 1.5 \mathrm{kPa}$, and (r) $60 \mathrm{rpm} 2.0 \mathrm{kPa}$.

\subsection{Multivariate Test}

\subsubsection{Test Method}

To study the influence of rotational speed, negative pressure, and aperture diameter on seed discharging accuracy, an orthogonal test was conducted to investigate the seed discharging performance based on the above-mentioned adsorption test of rice seeds by different diameter apertures. Here, we defined $2 \pm 1$ seeds per hole as the qualified quantity and statistically analyzed the influence of each factor on the seed discharging performance. Test conditions: the outer drum diameter $135 \mathrm{~mm}$; 8 sets of suction holes circumferential direction, $1.5 \mathrm{~mm}$ straight holes, $2 \mathrm{~mm}$ straight holes, and $2 \mathrm{~mm}$ holes with chamfer $45^{\circ}$; a negative pressure range of $1.0 \sim 2.0 \mathrm{kPa}$; and a speed range of $10 \sim 60 \mathrm{rpm}$. The test arrangements are shown in Table 3.

The results of the experiment were statistically analyzed using SPSS software and the probabilities for different numbers of seeds in the holes were recorded as shown in Table 4.

Table 4. The experiment arrangement and test results

$\operatorname{L18}\left(6 \times 3^{6}\right)$.

\begin{tabular}{|c|c|c|c|c|c|c|c|c|c|}
\hline Treatment & A Speed & $\begin{array}{c}\text { B } \\
\text { Negative } \\
\text { Pressure }\end{array}$ & $\begin{array}{c}\text { C Bore } \\
\text { Size }\end{array}$ & $\begin{array}{c}0 \text { Seed } \\
\text { Rate } / \%\end{array}$ & $\begin{array}{l}1 \text { Seed } \\
\text { Rate/\% }\end{array}$ & $\begin{array}{l}2 \text { Seed } \\
\text { Rate/\% }\end{array}$ & $\begin{array}{c}3 \text { Seed } \\
\text { Rate/\% }\end{array}$ & $\begin{array}{c}\geq 4 \text { Seed } \\
\text { Rate } / \%\end{array}$ & $\begin{array}{c}\text { 1-3 Seed } \\
\text { Rate/\% }\end{array}$ \\
\hline 1 & 1 & 1 & 1 & 9.6 & 63.0 & 23.1 & 4.3 & 0 & 90.40 \\
\hline 2 & 1 & 2 & 2 & 0.3 & 20.1 & 49.7 & 20.7 & 9.2 & 90.50 \\
\hline 3 & 1 & 3 & 3 & 15.5 & 21.7 & 28.3 & 22.0 & 12.5 & 72.00 \\
\hline 4 & 2 & 1 & 1 & 10.9 & 63.5 & 24.3 & 1.3 & 0 & 89.10 \\
\hline 5 & 2 & 2 & 2 & 0.3 & 31.3 & 50.3 & 15.1 & 3.0 & 84.70 \\
\hline 6 & 2 & 3 & 3 & 4.7 & 11.0 & 39.3 & 25.0 & 20.0 & 75.30 \\
\hline 7 & 3 & 1 & 2 & 2.6 & 63.8 & 30.9 & 2.6 & 0 & 97.40 \\
\hline 8 & 3 & 2 & 3 & 39.1 & 33.2 & 16.1 & 8.6 & 3.0 & 57.90 \\
\hline 9 & 3 & 3 & 1 & 13.8 & 54.6 & 25.7 & 5.3 & 0.7 & 85.50 \\
\hline 10 & 4 & 1 & 3 & 63.2 & 28.3 & 7.6 & 0.7 & 0.3 & 36.50 \\
\hline 11 & 4 & 2 & 1 & 22.3 & 65.1 & 12.6 & 0 & 0 & 77.70 \\
\hline 12 & 4 & 3 & 2 & 14.1 & 41.8 & 41.4 & 2.6 & 0 & 85.90 \\
\hline 13 & 5 & 1 & 2 & 17.4 & 65.8 & 16.1 & 0.7 & 0 & 82.60 \\
\hline 14 & 5 & 2 & 3 & 49.3 & 32.9 & 12.8 & 3.9 & 1.0 & 49.70 \\
\hline 15 & 5 & 3 & 1 & 46.1 & 48.7 & 5.3 & 0 & 0 & 53.90 \\
\hline 16 & 6 & 1 & 3 & 96.7 & 3.3 & 0 & 0 & 0 & 3.30 \\
\hline 17 & 6 & 2 & 1 & 66.4 & 30.6 & 3.0 & 0 & 0 & 33.60 \\
\hline 18 & 6 & 3 & 2 & 70.1 & 29.3 & 0.6 & 0 & 0 & 29.90 \\
\hline
\end{tabular}




\subsubsection{Test Results Analysis}

Due to the strong tiller capacity of hybrid rice, $2 \pm 1$ seeds per hole is generally more appropriate for field direct seeding, so $2 \pm 1$ seeds per hole is defined as qualified, 0 seeds per hole is defined as missing, and $\geq 4$ seeds per hole is defined as re-seeding.

(1) Influence on seeding qualified rate

From the analysis of Table 5, the R-values indicate that the order of influence on the pass rate indicators was $A>C>B$. For the analysis of increasing the pass rate, $A_{1} B_{1} C_{2}$ is the best combination. From the ANOVA in Table 6, factors $A$ and $C$ have a significant effect on the pass rate compared to factor $\mathrm{B}$.

Table 5. The intuitionistic analysis for qualified rate.

\begin{tabular}{cccc}
\hline Factor & A & B & C \\
\hline$k_{1}$ & 488.58 & 199.50 & 215.28 \\
$k_{2}$ & 498.18 & 197.04 & 235.5 \\
$k_{3}$ & 482.4 & 161.19 & 147.33 \\
$k_{4}$ & 400.02 & & \\
$k_{5}$ & 372.36 & & \\
$k_{6}$ & 131.76 & 66.55 & 71.76 \\
$\overline{k_{1}}$ & 84.30 & 65.68 & 78.50 \\
$\overline{k_{2}}$ & 83.03 & 53.73 & 49.11 \\
$\overline{k 3}$ & 80.40 & & \\
$\overline{k_{4}}$ & 66.70 & & \\
$\overline{k_{5}}$ & 62.06 & 12.82 & $\mathrm{~B}$ \\
$\bar{k}$ & 21.96 & $\mathrm{C}$ & \\
$R$ & 62.34 & $\mathrm{~A}$ &
\end{tabular}

Table 6. The variance analysis for the qualification rate.

\begin{tabular}{cccccc}
\hline Source & Type III Sum of Squares & df & Mean Square & F & Sig. \\
\hline Correction model & $11,129.028 \mathrm{a}$ & 9 & 1236.559 & 11.100 & 0.001 \\
Intercept distance & $79,507.427$ & 1 & $79,507.427$ & 713.716 & 0.000 \\
A & 8279.023 & 5 & 1655.805 & 14.864 & 0.001 \\
B & 6.524 & 2 & 3.262 & 0.029 & 0.971 \\
C & 2843.481 & 2 & 1421.741 & 12.763 & 0.003 \\
Error (Inaccuracy) & 891.194 & 8 & 111.399 & & \\
Total & $91,527.650$ & 18 & & \\
Total corrected & $12,020.223$ & 17 & & \\
\hline
\end{tabular}

(2) Influence on the missing rate

From the analysis of Table 7, the R-values indicate that $\mathrm{A}>\mathrm{C}>\mathrm{B}$ in the order of priority for the indicators of sowing failure, and that $A_{2} B_{3} C_{2}$ was the best combination for increasing the sowing failure rate. From the ANOVA in Table 8, factors A and C are more significant than factor $\mathrm{B}$ in influencing the sowing rate.

(3) Influence on the rate of re-seeding

From the analysis in Table 9, the R-values indicate that the main order of influence on the reseeding rate indicators was $\mathrm{A}>\mathrm{C}>\mathrm{B}$. The analysis for increasing the reseeding rate indicates that $A_{3} B_{1} C_{1}$ was the best combination. From the ANOVA in Table 10, the factors $\mathrm{ABC}$ did not have a significant effect on the reseeding rate. 
Table 7. The intuitionistic analysis for the missing rate.

\begin{tabular}{cccc}
\hline Factor & A & B & C \\
\hline$k_{1}$ & 25.40 & 200.40 & 215.28 \\
$k_{2}$ & 15.90 & 177.70 & 173.70 \\
$k_{3}$ & 55.50 & 164.30 & 268.50 \\
$k_{4}$ & 99.60 & & \\
$k_{5}$ & 112.8 & & \\
$k_{6}$ & 233.2 & 33.40 & 35.88 \\
$\overline{k_{1}}$ & 8.47 & 29.62 & 28.95 \\
$\frac{k_{2}}{k_{3}}$ & 5.30 & 27.38 & \\
$\overline{k_{4}}$ & 18.50 & & \\
$k_{5}$ & 33.20 & & \\
$\overline{k 6}$ & 37.60 & & \\
$R$ & 77.73 & 6.02 & $\mathrm{~B}$ \\
\hline
\end{tabular}

Table 8 . The variance analysis for the missing rate.

\begin{tabular}{cccccc}
\hline Source & Type III Sum of Squares & df & Mean Square & F & Sig. \\
\hline Correction model & $13,035.533 a$ & 9 & 1448.393 & 11.117 & 0.001 \\
Intercept distance & $16,344.320$ & 1 & $16,344.320$ & 125.447 & 0.000 \\
A & $10,657.167$ & 5 & 2131.433 & 16.359 & 0.001 \\
B & 111.003 & 2 & 55.502 & 0.426 & 0.667 \\
C & 2267.363 & 2 & 1133.682 & & \\
Error (Inaccuracy) & 1042.307 & 8 & 130.288 & & \\
Total & $30,422.160$ & 18 & & \\
Total corrected & $14,077.840$ & 17 & & & \\
\hline
\end{tabular}

Table 9. The intuitionistic analysis for re-seeding rate.

\begin{tabular}{cccc}
\hline Factor & A & B & C \\
\hline$k_{1}$ & 21.70 & 0.30 & 0.70 \\
$k_{2}$ & 23.00 & 16.20 & 12.20 \\
$k_{3}$ & 3.70 & 33.20 & 36.80 \\
$k_{4}$ & 0.30 & & \\
$k_{5}$ & 1.00 & & \\
$k_{6}$ & 0.00 & 0.05 & 0.12 \\
$\overline{k_{1}}$ & 7.23 & 2.70 & 2.03 \\
$\overline{k_{2}}$ & 7.56 & 5.53 & 6.13 \\
$\overline{k 3}$ & 1.23 & & \\
$\overline{k_{4}}$ & 0.1 & & 6.01 \\
$\overline{k_{5}}$ & 0.33 & & $\mathrm{~B}$ \\
$\overline{k 6}$ & 0.00 & 5.48 & \\
$R$ & 7.56 & $\mathrm{C}$ & \\
Factor Priorities & $\mathrm{A}$ & & \\
Optimization options & $\mathrm{A}_{3} \mathrm{~B}_{1} \mathrm{C}_{1}$ & & \\
\hline
\end{tabular}


Table 10. The variance analysis for the over sowing rate.

\begin{tabular}{cccccc}
\hline Source & Type III Sum of Squares & df & Mean Square & F & Sig. \\
\hline Correction model & $404.598 \mathrm{a}$ & 9 & 44.955 & 3.031 & 0.067 \\
Intercept distance & 137.227 & 1 & 40.199 & 2.253 & 0.016 \\
A & 200.996 & 5 & 45.117 & 3.042 & 0.101 \\
B & 90.234 & 2 & 56.684 & 3.822 & 0.104 \\
C & 113.368 & 2 & 14.831 & & \\
Error (Inaccuracy) & 118.644 & 8 & & \\
Total & 660.470 & 18 & & \\
Total corrected & 523.243 & 17 & & \\
\hline
\end{tabular}

\subsection{Seed Row Uniformity Test}

On the basis of the previous performance test of the vacuum drum-metering device, to test the difference in the seeding quantity between different the tubes (rows), the hybrid rice seed Wufengyou 615 that is cultivated by the Rice Research Institute of Guangdong Academy of Agricultural Sciences of China was used as the test material. The seeding amount uniformity test was carried out under the test conditions of negative pressure of $3 \mathrm{kPa}$ and $5 \mathrm{rpm}$, with the seed ports numbered from left to right as row 1, 2, 3, 4, and 5 metering devices that were inoculated with net bags that were continuously recorded for $10 \mathrm{~min}$, repeated three times, and recorded for groups A, B, and C, respectively. These were then weighed, tared, and averaged; the test set-up is shown in Figure 10 and the results that were recorded for the test are shown in Table 11.

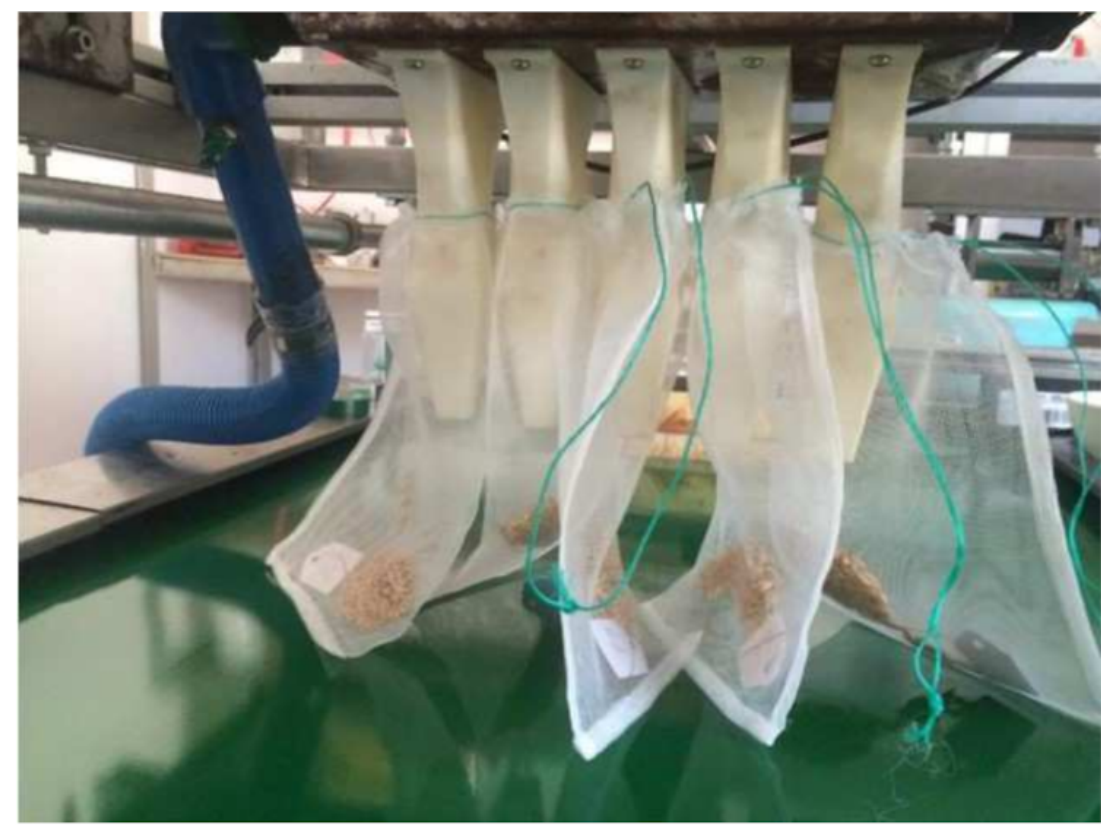

Figure 10. The seeding quantity uniformity test of row metering.

Table 11. Experimental data of the seeding quantity uniformity.

\begin{tabular}{ccccccccc}
\hline Repeat & \multicolumn{4}{c}{ Seed Quantity/g } & \multirow{2}{*}{ Mean/g } & SD & CV \\
& $\mathbf{1}$ & $\mathbf{2}$ & $\mathbf{3}$ & $\mathbf{4}$ & $\mathbf{5}$ & & $\mathbf{2}$ & \\
\hline A & 85.561 & 68.643 & 81.86 & 64.988 & 69.778 & 74.17 & 8.04 & $10.84 \%$ \\
B & 73.823 & 73.517 & 87.26 & 81.449 & 66.842 & 76.58 & 7.07 & $9.23 \%$ \\
C & 78.17 & 87.26 & 72.05 & 90.008 & 69.595 & 79.42 & 8.07 & $10.16 \%$ \\
Average seed quantity & 79.18 & 76.47 & 80.39 & 78.81 & 68.74 & 76.72 & 4.19 & $5.45 \%$ \\
\hline
\end{tabular}


As can be seen from Table 12 and Figures 11-14, the seed amount in rows that are closer to the negative pressure inlet was higher than in the rows that were further away, with a mean amount of $76.72 \mathrm{~g}$, a standard deviation of 4.19 , and a coefficient of variation of $5.45 \%$ for the three sets of trials.

Table 12. Fitting equation of the seed throwing trajectory.

\begin{tabular}{ccc}
\hline Seeding Drum Speed/(rpm) & Fitting Equation for Seeding Trajectory $\mathbf{Y}$ & ${\text { Correlation Coefficient } \mathbf{R}^{\mathbf{2}}}^{\mathbf{C}^{2}}$ \\
\hline 10 & $Y=-0.801 X^{2}+21.286 X-140.874$ & 0.990 \\
15 & $Y=-0.250 X^{2}-0.736 X+66.758$ & 0.995 \\
20 & $Y=-0.715 X^{2}+17.541 X-101.873$ & 0.995 \\
25 & $Y=-0.067 X^{2}-2.616 X+53.481$ & 0.999 \\
30 & $Y=-0.102 X^{2}+1.853 X+6.633$ & 0.990 \\
35 & $Y=-0.059 X^{2}-0.638 X+20.513$ & 0.998 \\
40 & $Y=-0.056 X^{2}+0.051 X+20.973$ & 0.998 \\
45 & $Y=-0.063 X^{2}+1.295 X+2.886$ & 0.999 \\
50 & $Y=-0.034 X^{2}-1.321 X+41.749$ & 0.999 \\
65 & $Y=-0.029 X^{2}-0.496 X+28.463$ & 0.999 \\
\end{tabular}

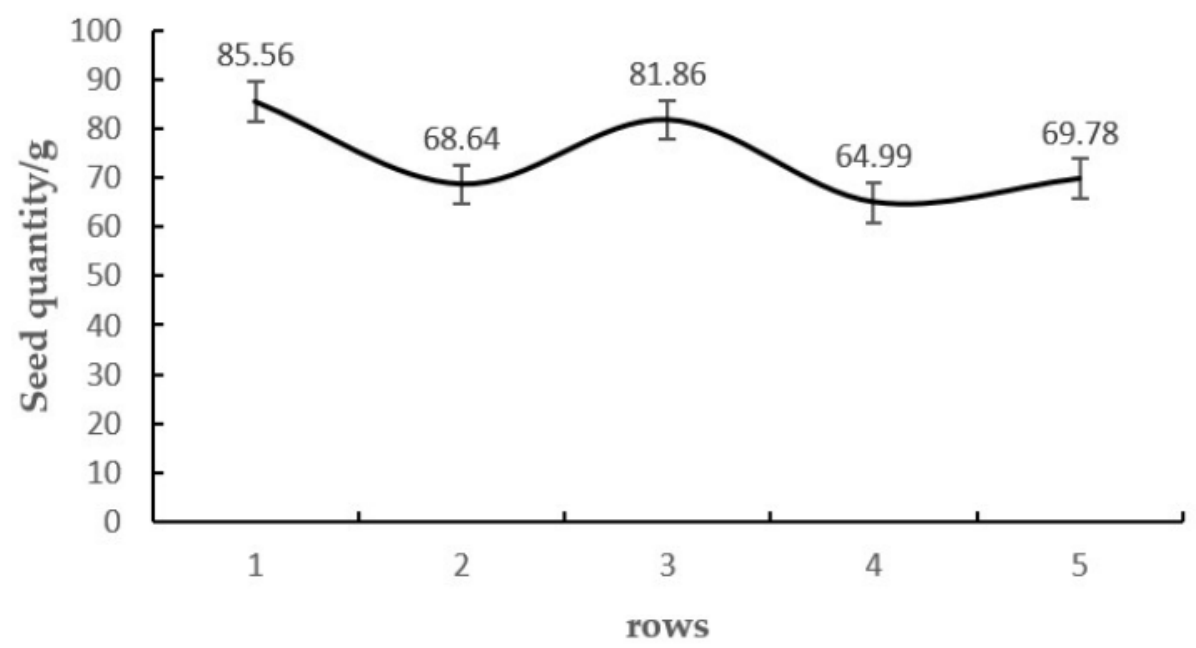

Figure 11. The graph chart of the seeding amount for the different sowing tubes in group A.

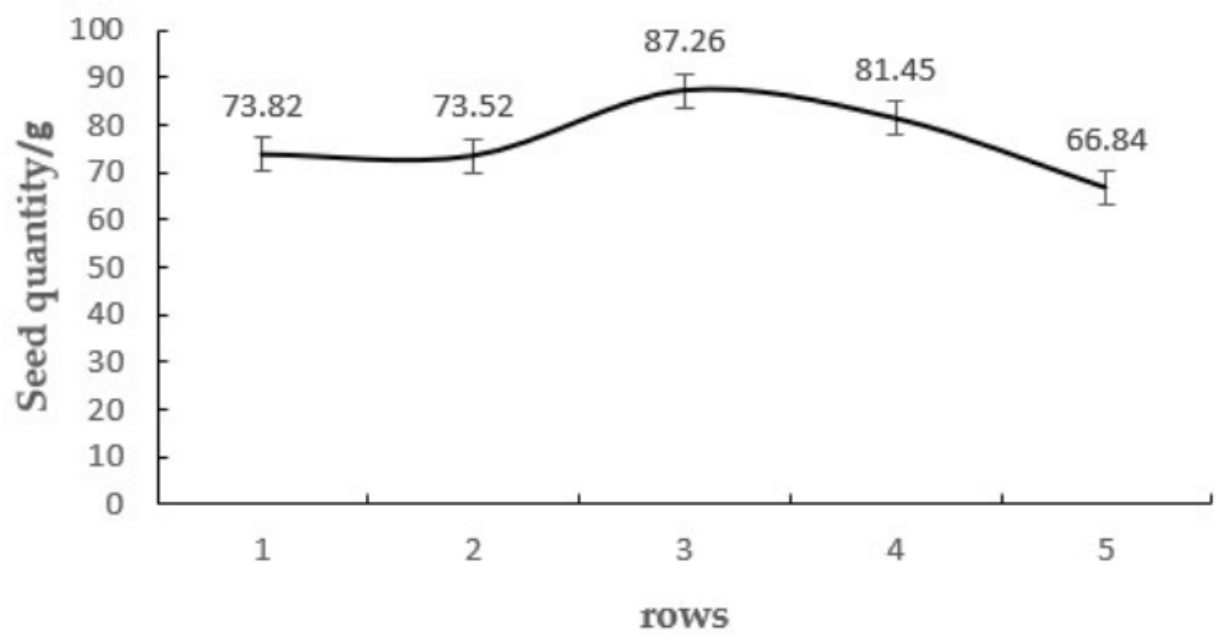

Figure 12. The graph chart of the seeding amount for the different sowing tubes in group B. 


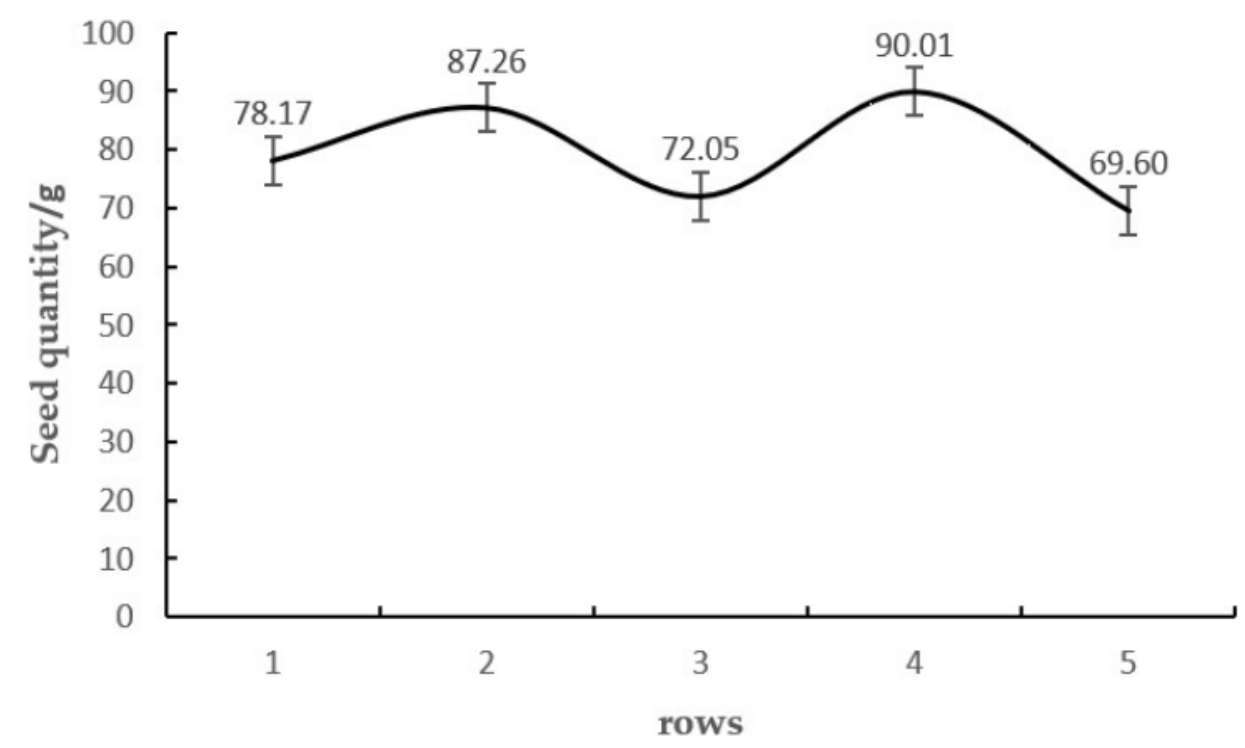

Figure 13. The graph chart of the seeding amount for the different sowing tubes in group C.

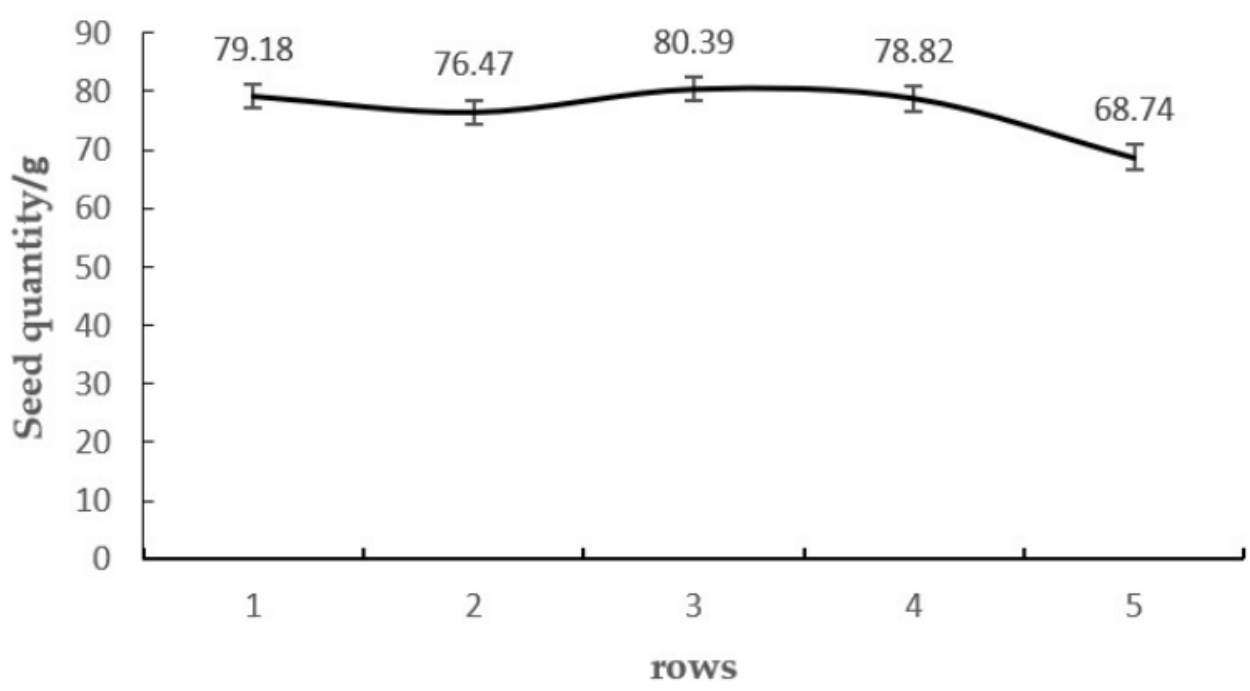

Figure 14. The graph chart of the seeding amount for the different seeding tubes in average.

The seed dropping trajectory of the vacuum drum metering device is an important basis for the design of the seeding tube structure. The design of the seeding drum structure and ventilation housing affected the seed trajectory and the initial speed of seed dropping. As such, the study of the seeding trajectory is important for the design of the seed-metering device. In this paper, the trajectory of the rice seed was studied by using high-speed camera technology to optimize the seed trajectory according to the curve. The model was simplified and the geometric centre of the single seed was used as the object of study. The high-speed camera test device is shown in Figure 15.

The background of the seed track was a back plate with a $5 \times 5 \mathrm{~mm}$ grid. The upper edge of the back plate was tangential to the bottom of the drum, leaving a $1 \mathrm{~mm}$ gap, and the camera shot at a frame rate of $125 \mathrm{fps}$, with a resolution of $1024 \times 1024$ pixels. The software interface shown in Figure 16. 


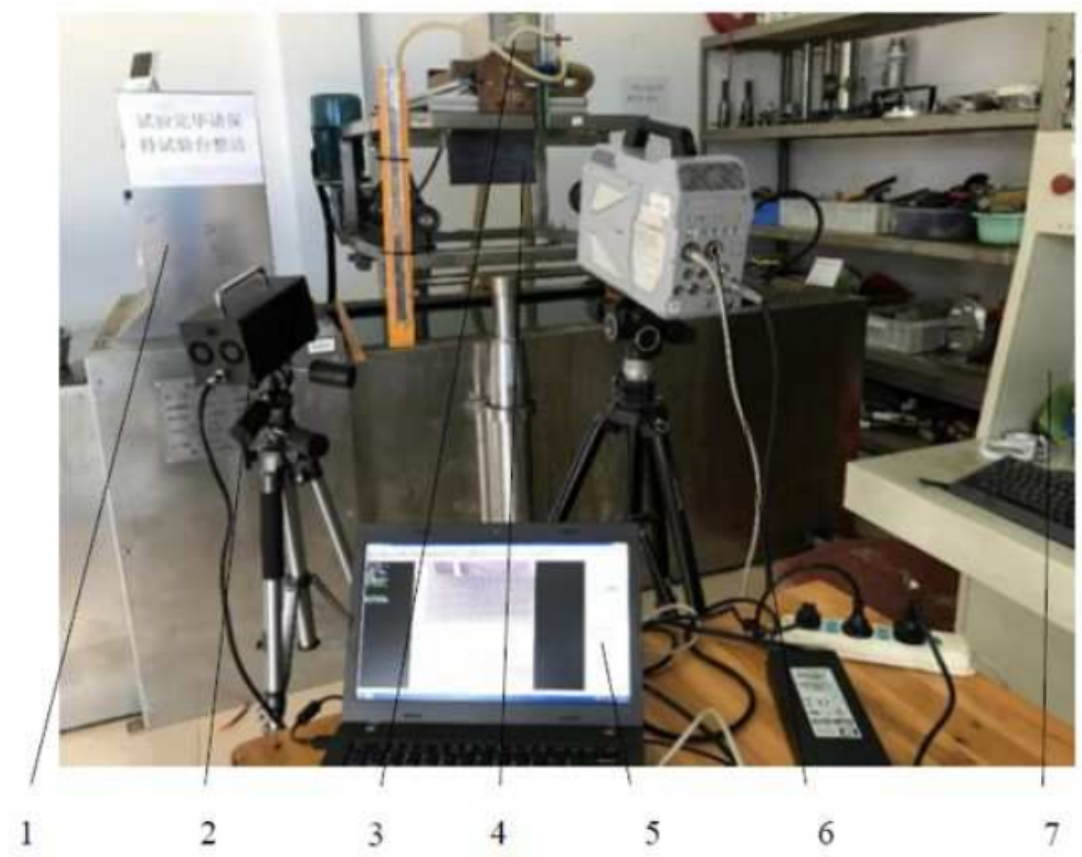

Figure 15. The high-speed photography test-bed for seed dropping trajectory. 1 . The metering device test-bed, 2. fill-in light, 3. the metering device, 4. the grid plate, 5. the computer, 6 . the high speed camera, and 7 . the operating platform.

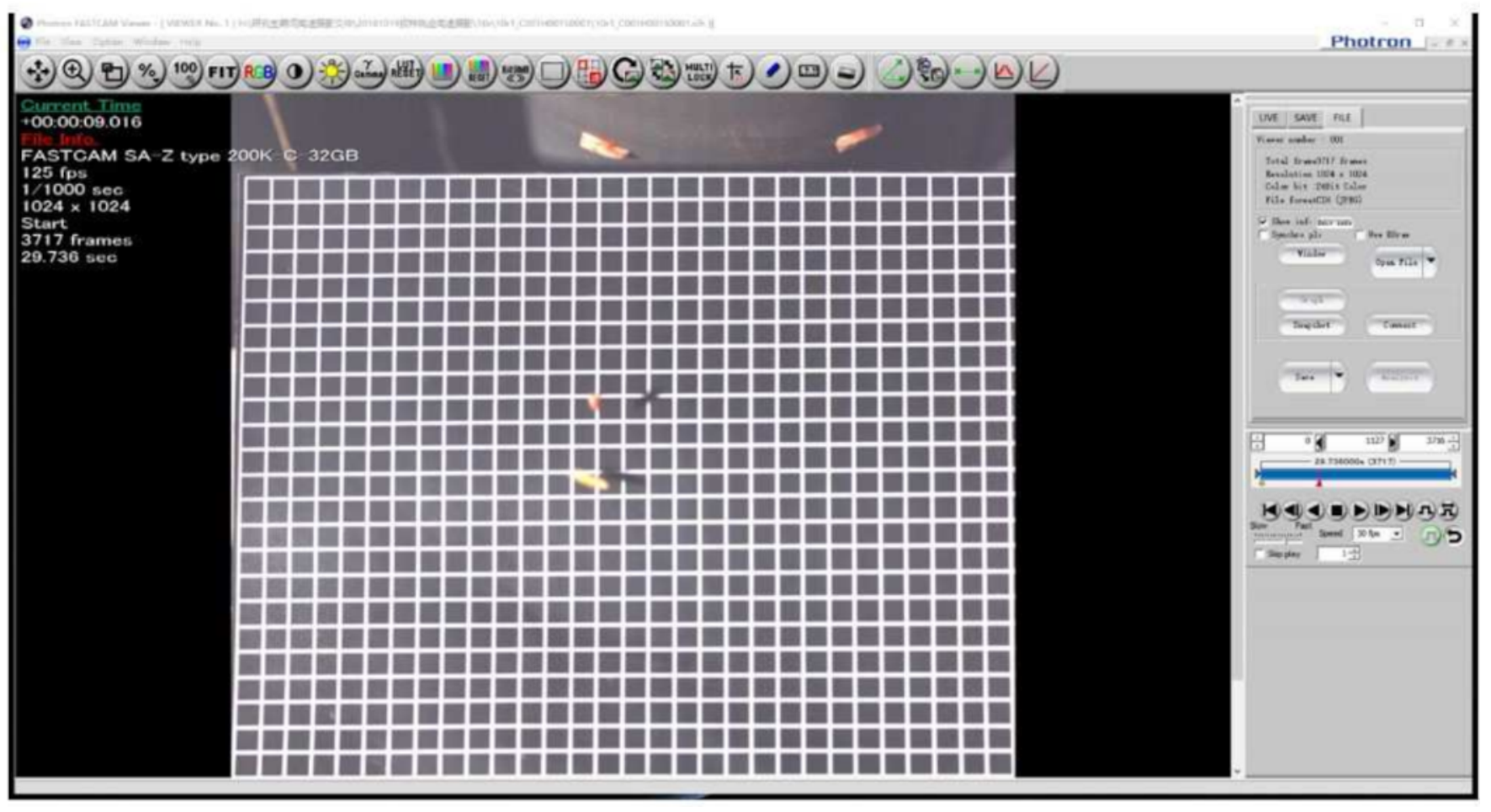

Figure 16. The Photron Fastcam viewer for high-speed digital imaging.

From the moment when the rice seeds appeared on the grid plate as the starting time, each frame was recorded continuously until the rice seed trajectory was out of the black grid plate, and the trajectory of the dropped rice seeds was recorded for six different drum speeds from 10 60 rpm, respectively. According to the research results of the related literature, the trajectory of the dropped rice seeds after the drum was only related to its speed $\omega$. The coordinates of the geometric centre of the dropped rice seeds were obtained 
through the high-speed camera, and the EXCEL software was used to create the trajectory of the dropped rice seeds in the range of 10 60 rpm, as shown in Figure 17.

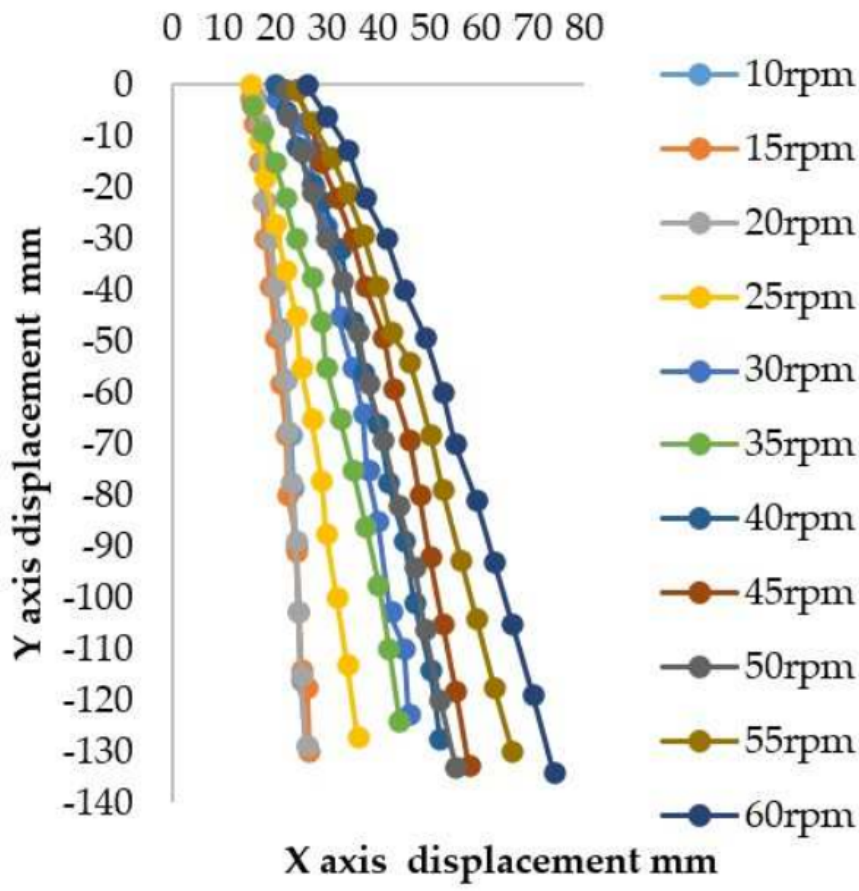

Figure 17. The dropping trajectory $t$ of the rice seeds.

Based on the seed trajectory in Figure 17, a curve regression was fitted using the statistical data analysis software SPSS as shown in Table 12. This shows that the correlation between the fitted equations for the seed trajectory of the seed dispenser from the drum speed of 10 60 rpm was well fitted.

According to the rice seed trajectory and fitting equation, the seed tube was drawn by 3D designing software and made by a 3D-printing machine, which can reduce the collision between the rice seed and the wall of the seed tube, and the uniformity of the seeds in furrows can be enhanced. The 3D drawings and printed model are shown in Figure 18, which laid the foundation for the field distribution test of the rice seed.
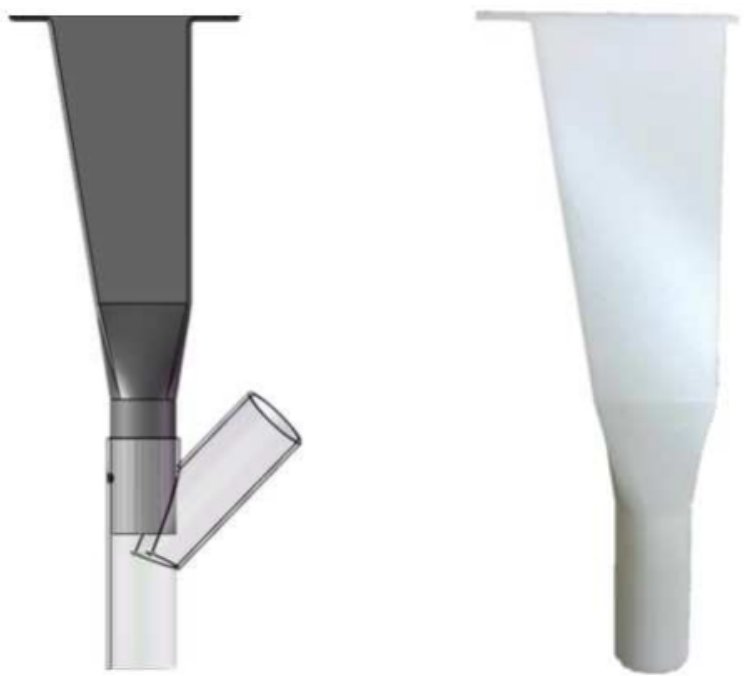

Figure 18. The view of the optimized seed tube and its 3D printed model. 


\section{Discussion}

To improve the level of lightened and simplified mechanization of hybrid rice seeding in China, this paper adopted a combination of theoretical calculation, parametric design, and a bench test to design a vacuum central drum seed-metering device. The test results show that the developed metering device can meet the design objectives, reducing the number of conventional seed-metering devices, and high demanding for vacuums.

(1) The technical requirements of the hybrid rice vacuum drum seed-metering device were determined according to the agronomic characteristics of hybrid rice, $2 \pm 1$ seeds per suction hole was defined as qualified, 0 seeds as missed, and $\geq 4$ seeds as reseeding. The suction performance of the vacuum central drum seed-metering was studied, and the suction amount performance of the drum seed was studied for different rotational speeds, different negative suction pressures, and different positive pressures.

(2) The double drum design allows for easy replacement of the outer drum with different types of holes, which helps to improve the adaptability to different varieties of rice or other crops and provides a basis for further adaptability studies.

(3) The use of distributed seed guide tubes can be adapted to the agronomic requirements of different row spacing. The form of distribution of the seed guide tubes, their angle, and the avoidance of sliding friction coefficients with the seeds all affect the distribution of the seeds in the field, which is the focus of future research.

\section{Conclusions}

In this paper, a vacuum central drum seed-metering device was designed by hybrid rice direct-seeding requirements. The main research conclusions are presented as follows:

(1) A vacuum central drum seed-metering device including double drums, ventilation housing, agitating device, and cleaning devices was designed. The main structural parameters of the seed-metering device were determined through theoretical analysis and experimental research. There are two areas of positive and negative pressure that are opened inside the ventilation housing; The inner drum is provided with 8 groups, 5 rows of flow channels with and a length of $340 \mathrm{~mm}$. The outer drum has a diameter of $135 \mathrm{~mm}$ and a length of $350 \mathrm{~mm}$. The outer drum is nested with the inner drum. Different types of shaped holes are opened on the outer drum, concentric with the inner shaped holes, and can be replaced according to different seed requirements.

(2) The performance of the seed-metering device was tested by single-factor and multifactor tests. The results show that the primary and secondary order of influencing the qualification rate index was $A>C>B$, and $A_{1} B_{1} C_{2}$ was the best combination for improving the qualification rate; the primary and secondary order of influencing the missed seeding rate index was $A>C>B$, and $A_{2} B_{3} C_{2}$ was the best combination for improving the missed seeding rate; the primary and secondary order of influencing the replay rate index was $\mathrm{A}>\mathrm{C}>\mathrm{B}$, and for improving the missed seeding rate. The analysis of improving the replay rate showed that $A_{3} B_{1} C_{1}$ was the best combination. The uniformity test of seed-metering in each row showed that the seed-metering in the row that was close to the negative pressure inlet was higher than that in the row that was far away. The average seed-metering in the three groups was $76.72 \mathrm{~g}$, the standard deviation was 4.19 , and the coefficient of variation was $5.45 \%$.

(3) The trajectory of seeds that were dropped was studied by means of high-speed camera technology. The $5 \mathrm{~mm} \times 5 \mathrm{~mm}$ grid coordinate plate recorded the dropping coordinates at different times, using EXCEL software to draw the seed dropping trajectory, carried out fitting equations, drew the three-dimensional structure model of the seed-metering tube through the equation of the dropping trajectory, and printed the seed-metering tube with 3D technology to ensure better uniformity of seeds in furrows. 


\title{
7. Patents
}

Three patents have been applied in China in this manuscript (Patent No. CN201610027 389.8, No. CN201721420260.X and No. CN201620577827.3).

\begin{abstract}
Author Contributions: Conceptualization, Z.W.; methodology, B.W.; software, B.W.; validation, Y.N.; formal analysis, B.W.; investigation, Y.N.; resources, Z.W.; data curation, Y.N.; writing—original draft preparation, Y.N.; writing—review and editing, B.W.; visualization, Y.N.; supervision, J.L.; project administration, Z.W.; funding acquisition, B.W. All authors have read and agreed to the published version of the manuscript.
\end{abstract}

Funding: This research was supported by Hainan Provincial Natural Science Foundation of China, grant number 520RC551; Hainan University Scientific Research Fund, grant number KYQD(ZR)20054

Institutional Review Board Statement: Not applicable.

Informed Consent Statement: Not applicable.

Data Availability Statement: All data are presented in this article in the form of figures and tables.

Conflicts of Interest: The authors declare no conflict of interest.

\section{Nomenclature}

DEM Discrete Element Method

d Suction hole diameter

$b \quad$ Average thickness of rice seeds

$Q_{m} \quad$ Displacement per second, $\mathrm{s}$.

$V_{g} \quad$ Linear speed of the drum, $\mathrm{m} / \mathrm{s}$.

D Diameter of suction hole, $\mathrm{m}$.

$\Delta L \quad$ Arc length between holes, $\mathrm{m}$.

$V_{m} \quad$ Speed of metering device advance, $\mathrm{m} / \mathrm{s}$.

$T \quad$ Distance between sowing plants, $m$.

$D_{g} \quad$ Drum diameter, $\mathrm{m}$.

$N \quad$ Speed of drum, rpm.

Z Number of suction holes, pcs.

rpm Seed-metering speed

PTO Power take off

ABS Acrylonitrile Butadiene Styrene plastic

fps Photos per second

\section{References}

1. Luo, X.; Jiang, E.; Wang, Z.; Tang, X.; Li, J.; Chen, W. Precision rice drilling machine. Trans. Chin. Soc. Agric. Eng. 2008, 24, 52-56.

2. Zeng, S.; Tang, H.; Luo, X.; Ma, G.; Wang, Z.; Zang, Y.; Zhang, M. Design and experiment of precision rice drilling machine for dry land with synchronous fertilizing. Trans. Chin. Soc. Agric. Eng. 2012, 28, 12-19.

3. Singh, R.; Gite, L. Technological Change in Paddy Production: A Comparative Analysis of Traditional and Direct Seeding Methods of Cultivation. AMA-Agric. Mech. Asia Afr. Lat. Am. 2012, 43, 41-46.

4. Dixit, A.; Manes, G.; Singh, A. Evaluation of direct-seeded rice drill against Japanese manual transplanter for higher productivity in rice. Indian J. Agric. 2010, 80, 884-887.

5. National Bureau of Statistics of the People's Republic of China. Annual Data, Rice Sown Area (Thousand Hectareas). Available online: https:/ / data.stats.gov.cn/easyquery.htm? $\mathrm{cn}=\mathrm{C} 01$ (accessed on 1 December 2021).

6. Hu, Z.; Tian, Y.; Xu, Q. Review of Extension and Analysis on Current Status of Hybrid Rice in China. Hybrid Rice 2016, 312, 1-8.

7. Zhang, G.; Zang, Y.; Luo, X.; Wang, Z.; Li, Z. Line-agitating tooth design and metering accuracy experiment of rice vacuum precision hill-drop seed metering device on pregnant Japonica rice seed. Trans. Chin. Soc. Agric. Eng. 2014, 30, 1-9.

8. Zhang, G.; Zang, Y.; Luo, X.; Wang, Z.; Zhou, Z. Design and experiment of oriented seed agitating device on vacuum seed metering device for rice. Trans. Chin. Soc. Agric. Eng. 2013, 29, 1-8.

9. Zhang, G.; Luo, X.; Zang, Y.; Wang, Z.; Zeng, S.; Zhou, Z. Experiment of sucking precision of sucking plate with group holes on rice vacuum metering device. Trans. Chin. Soc. Agric. Eng. 2013, 29, 13-20.

10. Xing, H.; Zang, Y.; Wang, Z.; Luo, X.; Zhang, G.; Cao, X.; Gu, X. Design and experiment of stratified seed- filling room on rice vacuum metering device. Trans. Chin. Soc. Agric. Eng. 2015, 31, 42-48. 
11. Lei, X.; Liao, Y.; Li, Z.; Zhang, W.; Li, S.; Liao, Q. Design of seed agitating device in air-assisted centralized metering device for rapeseed and wheat and experiment on seed filling performance. Trans. Chin. Soc. Agric. Eng. 2016, 32, 26-34.

12. Liu, Y.; Zhao, M.; Yang, T.; Zhang, T.; Li, F. Simulation and Optimization of Working Parameters of Air Suction Metering Device Based on Discrete Element. Trans. Chin. Soc. Agric. Mach. 2016, 47, 65-72.

13. Xiong, D.; Wu, M.; Xie, W.; Liu, R.; Luo, H. Design and Experimental Study of the General Mechanical Vacuum Combined Seed Metering Device. Appl. Sci. 2021, 11, 7223. [CrossRef]

14. Guo, H.; Cao, Y.; Song, W.; Zhang, J.; Wang, C.; Wang, C.; Yang, F.; Zhu, L. Design and Simulation of a Garlic Seed Metering Mechanism. Agriculture 2021, 11, 1239. [CrossRef]

15. Zhao, Z.; Li, Y.; Chen, J.; Zhou, H. Dynamic analysis on seeds pick-up process for vacuum-drum seeder. Trans. Chin. Soc. Agric. Eng. 2011, 27, 112-116.

16. Zuo, Y.; Ma, X.; Qi, L.; Yu, D.; Liao, X. Seeding experiments of suction drum- seeder with socket-slot. Trans. Chin. Soc. Agric. Eng. 2010, 26, 141-144.

17. Zuo, Y.; Ma, X.; Yu, D.; Liao, X. Flow Field Numerical Simulation of Suction Drum-seeder for Rice Bud Seed with Socket slot. Trans. Chin. Soc. Agric. Mach. 2011, 42, 58-62.

18. Gao, X.; Zhou, J.; Lai, Q. Design and experiment of vacuum precision seed- metering device for panax notoginsen. Trans. Chin. Soc. Agric. Eng. 2016, 32, 20-28.

19. Hu, J.; Zheng, S.; Liu, W. Design and Experiment of Precision Magnetic Drum-seeder. Trans. Chin. Soc. Agric. Eng. 2009, 3, 60-63.

20. Karayela, D.; Wiesehoffb, M.; Özmerzia, A. Laboratory measurement of seed drill seed spacing and velocity of fall of seeds using high-velocity camera system. Comput. Electron. Agric. 2006, 50, 89-96. [CrossRef]

21. Singh, R.; Singh, G.; Saraswat, D. Optimization of design and operational parameters of a vacuum seed metering device for planting cottonseeds. Biosyst. Eng. 2005, 92, 429-438. [CrossRef]

22. Furuhata, M.; Chosa, T.; Shioya, Y. Developing Direct Seeding Cultivation Using an Air-Assisted Strip Seeder. Jpn. Agric. Res. Q. Jarq 2015, 49, 227-233. [CrossRef]

23. Karayel, D.; Barut, Z.B.; Ozmerzi, A. Mathematical modelling of vacuum pressure on a precision seeder. Biosyst. Eng. 2004, 87, 437-444. [CrossRef]

24. Topakci, M.; Karayel, D.; Canakci, M. Sesameping Performance of a Vacuum Seeder for Different Tillage Practices. Appl. Eng. Agric. 2011, 27, 203-209. [CrossRef]

25. Wang, B.; Wang, Z.; Luo, X.; Zhang, M.; Fang, L.; Liu, S.; Xu, P. Design and experiment of wedge agitating device for vacuum drum-type seed metering device for hybrid rice. Trans. Chin. Soc. Agric. Eng. 2019, 35, 1-8.

26. Chinese Academy of Agricultural Mechanization Sciences. Agricultural Machinery Design Manual: Volume I.; Agricultural Science and Technology Press: Beijing, China, 2007.

27. GB-T 6973-2005; Testing Methods of Single Seed Drills (Precision Drill). China Standard Press: Beijing, China, 2005. 